\title{
La periferia en la biblioteca de Occidente
}

\section{The Periphery in the Western Library}

\author{
Antonio Becerra Bolaños \\ Universidad de Las Palmas de Gran Canaria \\ antonio.becerra@ulpgc.es \\ ORCID iD: http://orcid.org/0000-0002-3416-2871
}

\section{RESUMEN}

En principio, se pueden suponer cuáles son las obras que han de formar parte de una hipotética biblioteca de Occidente, a modo de la biblioteca borgesiana de Babel. Sin embargo, se podría incluir una serie de libros excluidos por su doble condición periférica, tanto geográfica (como Hispanoamérica) como cultural. Esas obras rara vez aparecieron consideradas en los diversos cánones de la literatura hispánica que se plantearon a partir del siglo XVIII, en muchas ocasiones por desconocimiento de aquellas, exceptuando a Menéndez Pelayo. El presente trabajo tiene como objetivo reflexionar acerca de cuáles han sido los criterios por los que la periferia ha permanecido en los márgenes de esa biblioteca y proponer un canon alternativo de acuerdo con esa condición, en tanto que lectura necesaria de una realidad común que presenta sus propias peculiaridades.

Palabras Clave: canon; periferia; literatura del siglo XIX; Menéndez Pelayo; Literatura Hispanoamericana.

\section{ABSTRACT}

In principle we could assume which works could be part of a hypothetical Western library, as the Borges' Library of Babel. However, we may include a series of books excluded by its peripheral condition, as much geographical (like Hispanic America) as cultural. These works rarely appeared to be considered in the various canons of Hispanic literature which arose in the XVIIIth century, often by lack of awareness of their existence (with the exception of Menéndez Pelayo). The objective of the present article is to reflect on the criteria used through which the peripheral works have remained on the margins of that library and to propose an alternative canon in accordance with this condition, in so far as necessary reading of a common reality with its own peculiarities.

Key words: Canon; Periphery; XIX Century Literature; Menéndez Pelayo; Hispanic American Literature. 
Sabido es que la tentación del canon, si se me permite llamarla así, hunde sus raíces en la tradición occidental desde antiguo. Sin embargo, la cuestión no ha tenido tanta visibilidad pública en el ámbito de las escrituras hispánicas (si exceptuamos casos como los de Borges o Alfonso Reyes, por citar dos ejemplos conocidos) como ha sucedido con la obra de Harold Bloom en el ámbito anglosajón. En el caso de Bloom, parece más producto de una afortunada elección del título y de la procedencia académica del canonizador que de un conocimiento profundo de aquellas realidades literarias que van más allá de lo que el autor considera lo occidental y sus influencias en obras posteriores, a tenor de algunos juicios que vierte (dudamos de su lectura del Quijote, leyendo la(s) página(s) que le dedica en su Novelas y novelistas. El canon de la novela (2012), realizada de una manera superficial; aunque entendemos más bien su interés en Estados Unidos y en el mundo anglosajón fundamentalmente, entendido como el Occidente).

No es mi intención cuestionar los criterios del prestigioso crítico estadounidense, pero sí su carácter exclusivo, al arrogarse un estatus que pocos han reclamado para sí. En este sentido, podríamos recordar, por ejemplo, las propuestas canónicas de Italo Calvino, Seis propuestas para el próximo milenio (2012) y Por qué leer los clásicos (1993), mucho menos excluyentes, o la de Carlos Fuentes con respecto de la novela latinoamericana (2011). Recientemente, al hilo de la «Biblioteca de Occidente», lista o canon planteado por Garrido Gallardo y que sirvió como punto de partida del congreso homónimo (La Biblioteca de Occidente en contexto hispánico), García Barrientos (2013) reflexionaba acerca de los aspectos histórico-lingüísticos que determinaban el canon y la preferencia en él de ciertos géneros literarios sobre otros (en concreto el teatro).

De todas maneras, no ha de extrañarnos que, bajo el epígrafe occidental, lo hispano se convierta en una suerte de periferia, como ya habían apuntado Enrique Dussel (1994) y, en la misma línea, Iris M. Zavala (2010), quien señala el «Occidente industrial» como objeto de influencia y molde que se aplica a todas las producciones culturales «sustantivas». No habría que olvidar que el liberalismo latinoamericano del XIX — con figuras como Alberdi, Sarmiento o Guzmán - sustentó la idea de que las naciones de la zona se transformaran «en replicantes de los considerados como indiscutibles modelos de desarrollo y civilización: Francia, Inglaterra o Estados Unidos» (Lasarte Valcárcel, 2003: 58). Grínor Rojo (2011). Asimismo, se plantea la apropiación de las manifestaciones literarias periféricas por parte de este canon, que no tienen que ver con las actualizaciones que se producen en determinadas obras al cambiar el contexto lector, como sucede con Galdós y su Tristana (Kronik, 2005), incluida en el canon elaborado por las feministas a partir de la película de Buñuel (Davis, 2001). Como este, podríamos encontrar muchos ejemplos.

No me interesan tanto las diferentes propuestas «canónicas» que se han realizado desde el siglo $\mathrm{XX}$, como la percepción de muchas producciones del 
siglo XIX entendidas como periféricas, alejadas del canon y que, por tanto, han padecido la inclusión dentro de los epígrafes de literaturas regionales o literaturas menores, de igual manera que Juaristi o Sánchez Robayna (1994) hicieron en el siglo XX, y que apuntan, en el caso de Robayna, a microtradiciones, y, en el de Juaristi, siguiendo a Deleuze y a Guattari, a una literatura que sigue sin discusión el canon y, por tanto, es una imitación del centro (literatura regional) o que propone cánones alternativos o usos literarios menores o excluidos (literatura menor). Si planteamos la propuesta de Juaristi a la literatura canaria, nos veríamos abocados a hablar de aquellos críticos y teóricos que se empeñan en aplicar los moldes canónicos de la literatura española a los autores de cualquier comunidad, con olvido de que los escritores de cualquier latitud son los que elaboran un canon al par de sus obras. Hay que subrayar entonces esa contingencia que condiciona en muchas ocasiones lo que se lee.

Ante estas posturas, tanto Rodríguez Padrón (2007) como Padorno (2003), entre otros, han señalado la necesidad de replantear esas consideraciones, porque, en el caso de Canarias y su producción literaria, estas manifestaciones culturales no sienten como propia la tradición a la que, políticamente, han de adscribirse. De esa manera, mientras los primeros niegan la autonomía de las literaturas periféricas, los segundos hacen patente las posibilidades de resonancia de la tradición.

Por mucho que queramos obviarlo, y aunque, como señala Díez Borque, detrás del canon está la memoria literaria, que «retiene del pasado unas cuantas obras» (2007: 181) que lo constituyen, este tiene una connotación política que incita a la confrontación. Así, no es de extrañar que el debate entre Literatura en mayúscula y literatura en minúscula se haya convertido en una batalla de privilegios entre dos concepciones nacionalistas - la del centro, la canónica, y la de la periferia-, algo que ha alejado de lo puramente estético una cuestión como la literaria; esto es, y como señala Juaristi (1994: 49), «el problema de la canonicidad desborda la Teoría de la Literatura e incide directamente en el terreno de las prácticas sociales». Sin embargo, como señala Rojo (2011: 12), circunscribirlo únicamente a ese ámbito puede resultar peligroso, ya que
Afirmar que tales o cuales autores y libros canónicos son irredimibles, y abando- narlos por eso a la pobreza y los prejuicios de la interpretación del politicastro o el gestor cultural de turno, equivale a afirmar que tales autores y tales textos pueden ser leídos de una manera y solo de una, y que esa manera no es otra que la que la máquina de dominio imperante ha impuesto sobre ellos o la que (y no hay por qué descuidar esta segunda alternativa) ellos se imponen a sí propios.

Los autores y las obras canónicas, leídas de una manera determinada, pueden resultar políticamente convenientes; pero ello no desvirtúa, en muchas ocasiones, su valor. Lo que sí sucede, en el ámbito de las historias críticas de la literatura, es que se enfoquen los debates sobre el carácter literario o no literario de las obras incluidas o excluidas en un determinado canon desde una 
perspectiva nacionalista, lo que haría mantener aquellos criterios que, primero en Quintana y posteriormente en Menéndez Pelayo, podrían prevalecer en la fijación de los cánones del XIX.

Teniendo en cuenta estas consideraciones, se podría afirmar que uno de los criterios válidos para la inclusión de una obra en un canon, que acabe formando parte de nuestra biblioteca, será la capacidad que posee esta de generar otros textos, idea que también está presente en autores como Alfonso Reyes (1997), para quien un somero rastreo de la Literatura Hispanoamericana para la elaboración de una o varias antologías temáticas nos ofrecería un amplio panorama de resonancias de este tipo. Esas resonancias varían de obra en obra, de lector en lector; como afirma Colinas (2002: 81),

Si seguimos con la operación de cerrar los ojos y de rescatar de la memoria señales valiosas, mundos que se han fijado luego en literatura, veremos que los libros aparecen como una constelación de significados. No hay solo un tipo de libros en nuestras vidas, sino tantos libros o grupos de libros como respuestas nos da el mundo. No solo tiene sentido aquel primer libro que leímos, o que regalamos o que sacamos de la biblioteca de la infancia, sino que el proceso de leer es infinito.

Ese proceso infinito, que ya había apuntado Borges, es el que señala Fuentes (2011: 160): «Y tú, el lector, eres el autor de Don Quijote porque cada lector crea su libro, traduciendo el acto finito de escribir en el acto infinito de leer».

La libertad de la escritura, como la libertad de la lectura o del lector, toma carta de naturaleza en la Ilustración, cuando, afirma Gadamer (1998: 345), comienza a combatirse «la falsa inclinación preconcebida en favor de lo antiguo, de las autoridades». Ese proceso es sumamente interesante puesto que no se niega el canon, sino que se discute. Si en un principio, se plantea que el escritor que no se halle incluido en el centro cultural ha de abandonar la expresión que le es propia — que le es «natural»-y ha de seguir el canon establecido, por ser aquel el que define el mundo en un determinado momento, con independencia de que sea aplicable a una realidad que no comparte los mismos elementos conformadores, el cuestionamiento de aquellos textos que formaban parte del prejuicio se ha de abandonar. No es algo que sea novedoso, ya que, desde las literaturas en segundo grado, tal como las ubica Genette, es una práctica que se viene realizando desde el pasado. Creo que no hay que nombrar ejemplos tan evidentes como El Quijote o las escrituras borgesianas, por no abandonar el ámbito hispánico en el que voluntariamente me adscribo.

No se encuentra demasiada literatura que trate el tema de la literatura periférica, concepto que sirve para señalar la posición que ocupa frente al canon, por ejemplo, la literatura juvenil (me viene a la memoria, por ejemplo, que Círculo de Lectores había publicado La peste de Camus en traducción de Rosa Chacel en su colección juvenil), incluida en la paraliteratura, concepto, cuanto 
menos, polémico, por no poder ser aplicado al pie de la letra a muchas obras (Lluch, 2009). No caeré en la tentación de entrar a discutirlo aquí.

Me interesa apuntar que, con periferia, designamos todo aquello que es ex-céntrico. La palabra evoca ciertamente una realidad geográfica que nos sirve asimismo para confrontar dos realidades o, si se quiere, dos espíritus (por situarme desde una perspectiva romántica, desde una perspectiva decimonónica). Sin embargo, esta misma noción nos sirve para evocar otra circunstancia. La periferia puede imitar al centro, de acuerdo con Deleuze/Juaristi, o puede buscar, directa o indirectamente, el impulso de aquel para desarrollarse. La afirmación del ser periférico tiene a veces que ver con la negación del ser céntrico o con su propia afirmación. Ahora bien, con periferia también podemos designar un espíritu que poco tiene que ver con lo puramente geográfico y que tiende sus lazos hacia la esfera de lo intelectual o a las manifestaciones estéticas de una época. Entonces la periferia puede ser aplicable al propio centro.

La parodia, por ejemplo, es en sí misma periferia. Se sitúa en los márgenes del centro que es el texto original. La parodia nunca se realiza sobre la base de un texto desconocido, sino de aquel cuyas ondas llegan hasta el momento de su escritura. Tiene su razón de ser en la existencia del centro, de lo que es culturalmente válido y se halla asumido por la mayoría, quizás por reclamar para sí misma la condición de centro; es decir, textos que se definen por su adscripción a otros textos o tradiciones reconocibles por el receptor de los mismos, que se adhiere a la postura evocada desde el texto por suponer una afirmación de su propia cultura.

El centro aquí está situado en una esfera puramente cultural, en tanto que referencia a la que se acude siempre o que, de manera consciente o inconsciente, está presente como generadora de toda una expresión. El Arma virumque cano de Virgilio se convierte en la impronta de un tipo determinado de expresión: lo épico. El modelo épico apunta hacia lo alto, hacia la nobleza de unas acciones en tanto que con ellas, o con la imitación de ellas, se define un tipo ideal que será imitado — ¿asimilado? - por sus receptores. De ahí que la parodia, en este caso, se convierta en una reescritura del canon, como representación del centro. La parodia en tanto que periferia se muestra como otra lectura de un texto que ha sido leído de una manera determinada hasta que encuentra una nueva enunciación. El libro que es se convierte, mediante sutiles cambios - el fin perseguido por el héroe, los personajes, sus acciones, el tiempo y el espacio en que estas transcurren; el modo en que se desarrollan-, en otro libro que refleja de manera absoluta la distancia que media entre el mito y la realidad. La periferia es entonces el espejo en el cual se mira el mito, es decir, el centro, para obtener la realidad. Las acciones de orden superior que aparecen en la epopeya, en la parodia se convierten en acciones inferiores y se descubre en ellas la menudencia del hombre. Mientras el hombre superior busca el beneficio de los otros, el ser común - ya sean el tesorero y el chantre, en el caso del poema Le lutrin de Boileau; la mole Estupidez, en $O$ reino da Estupidez de 
Melo Franco (1822); el hombre que roba un rizo, en The rape of the lock de Pope (1851), o una rosa, en el del conde de Noroña y su «Quicaida» (1997) busca su propio beneficio. La periferia entonces es el tiempo real del hombre — situado en su momento histórico - y se halla abocada a tener sentido en esas circunstancias. Menéndez Pelayo (1886: 188) escribe sobre estas obras:

La Quicaida del conde de Noroña, el Imperio de la Estupidez de Lista (imitación de la Dunciada), el Mesías de Blanco y otros muchos poemas que pudiéramos citar, acreditan cuán grande fué el estudio que se hizo de Pope, y la tendencia que había á imitarle y aun a plagiarle.

Boileau, por ejemplo, cuando escribe Le lutrin (1862), trata un hecho conocido por los habitantes de París de su época; Rabelais actúa sobre la base de una herencia común a todos sus lectores si bien, en su caso, la parodia logra independizarse del modelo para convertirse en centro, como también le sucede a Cervantes. Lo mismo podríamos decir de Melo Franco y su Reino da Estupidez, en el contexto de la reforma pombalina de Portugal, que tendrá eco en la obra homónima de Jorge de Sena (1961). Sin embargo, no solo la parodia literaria es periferia. Podríamos decir que ella es su génesis. La periferia se muestra como una manera de ser profundamente enraizada en el hombre. Así, los grandes autores se dirigen hacia ella para sacudirse de la gravedad del centro, algo que encontramos en Pérez Galdós constantemente (Rodríguez, 1966; Cabañas, 1967; Martínez Palacio, 1971; Schraibman, 1984; Bou, 1989; Juaristi, 1990; Román, 1990 y 2006; Ayala Aracil, 2005; Coffey, 2009), cuyas obras también fueron parodiadas por el cubano Fernando Ortiz (Gómez Castellano, 2010) y, como ha estudiado Peláez Pérez (2007), por Gabriel Merino ( $L a$ de Bringas, Electra y El abuelo), Salvador María Granés, Felipe Pérez (La de Bringas); Federico Escacena y Rafael Muñoz y Gabriel Merino (Electra); Antonio Casero y Alejandro Larrubiera (Mariúcha) o Manuel Fernández de la Fuente (El abuelo).

De una manera deliberada, me ubico en el siglo XIX, ya que con la posmodernidad usos como la parodia se han convertido en centro y han solapado en la periferia otras voces menores.

A la periferia pertenecen también autores a los que la crítica mantiene en el apartado de raros o incapaces en sus intentos de llegar a la altura de la gran literatura. Es conocido el caso de Silverio Lanza, de quien Gómez de la Serna, al igual que lo harían Juan Ramón Jiménez, Pío Baroja o Antonio Machado, se lamentaba del poco conocimiento que se tenía de este autor, al que consideraba, sin lugar a dudas, uno de los grandes de la literatura española. En ello no hay que ver ni un solo atisbo de ironía, ni siquiera el afán rupturista tan propio del ramoniano por antonomasia. Ciertamente, el propio Gómez de la Serna lo subraya (1985), sus historias no se sustentan; comete excesivos errores y, sin embargo, sigue apareciéndosele como una figura de indudable magnetismo; 
pero, ¿a qué se debe esa fascinación? Simplemente, al momento, a una sola frase o a una sola página, lo que, según el ramoniano por excelencia, valdría para colocarlo en el Parnaso y con los cuales se justifica su existencia. En Silverio Lanza es el impulso vital, la energía con la que se entrega a la literatura, lo realmente importante; en definitiva, el proyecto vital que supone su separación de quien realmente era para ser otro.

José de Viera y Clavijo, Clavijo y Fajardo, Nicolás Fernández de Moratín, Mesonero Romanos, Alcalá Galiano o Graciliano Afonso («Su afición a los versos era tan grande como infortunada, solo comparable con la de su paisano Viera y Clavijo», Menéndez Pelayo, 1886: 318) serían, por citar solo algunos conocidos del XVIII y del XIX, autores que no llegan a formar parte del canon. No existen sino para, de forma paralela, justificar a los otros. Su bajeza les impide pertenecer a aquella categoría y, sin embargo, son estos autores los que se sitúan en esa misma periferia. Se encuentran en el lugar más apartado de esa gran biblioteca babeliana, usados únicamente como excusa para que los propios críticos puedan desarrollar otro discurso ajeno al gran discurso crítico de los verdaderos autores.

La biblioteca ideal asusta no solo por su tamaño, sino por la cantidad de bibliotecas ideales en las que se puede convertir. Una obra como el Pedro Páramo se convierte en cerca de doscientas obras Pedro Páramo; un libro como El Quijote podría llegar tranquilamente a la cantidad de cien mil si no más libros. Por tanto, de la misma manera que el centro, es decir, el cuerpo mayor de esa gran biblioteca nuestra, crece, la periferia va convirtiéndose en el reflejo de ese centro, de ese canon, bien complementándolo, bien enfrentándose a él. Nuestra biblioteca debería ser capaz de asimilarlo todo y, sin embargo, no es así. Nuestra biblioteca se va convirtiendo en algo extraño a nosotros mismos. No solo porque en ella incluimos aquellas lecturas que con el paso de los años hemos ido acumulando y convirtiendo en propias, sino porque nos hemos ido apropiando de lecturas que nos llegan únicamente de forma indirecta y que, a mi entender, son de igual manera válidas. Ya no nos es preciso leer; simplemente nos basta con acumular. De ahí que la periferia se convierte en una manera de situarse frente a esta biblioteca. Si cada libro tiene su propio lector, es de justicia que todos y cada uno de los libros que existan o tienen la posibilidad de existir se nos presenten. Desde el mismo momento en que cada autor menciona una obra, esta se sitúa en la misma periferia de esa biblioteca ideal. No hemos de ver en ello un capricho, sino la necesidad por parte de ese autor de defender el lugar que ocupa en su propia biblioteca un libro - no importa si real o ficticio- que se establece en los márgenes, como si en él estuviera contenida una visión auténtica. Subraya así este autor su propio destino de lector. Cuando Goncourt ante la Academia francesa, de la que iba a entrar a formar parte, reconocía que no había leído una sola novela, no negaba su vocación de lector, sino que afirmaba su vocación periférica. 
No hace falta leer Don Quijote para decir que se ha leído. Cualquier persona sabe de qué trata en líneas generales. La biblioteca de Babel es tan amplia que permite la lectura del Quijote por, pongamos, Martín de Riquer, o la $\mathrm{Ce}$ lestina por Pedro Salinas, o Fuenteovejuna por Dámaso Alonso o El Poema de Mio Cid por Menéndez Pidal. Estas obras - la lectura propuesta de las mismas - no nos hacen dudar, sino que se complementan con las nuestras. El Poema de Mío Cid de Menéndez Pidal viene a enriquecer el mío.

Pero volvamos a plantear el problema de una literatura periférica. Distinguimos ya entre una periferia geográfica, por ejemplo, las Islas Canarias, y una periferia estética que no deja de estar relacionada con la geográfica, la literatura canaria - si en ella existen los elementos suficientes para que, dentro del contexto de las literaturas hispánicas, sea considerada como tal—; sin embargo, existe otra periferia de tipo estético mediante la cual, como hemos visto, el mito se convierte en realidad. A esta última periferia correspondería la parodia $\mathrm{y}$, dentro de esta, todos aquellos géneros y subgéneros que remiten de una forma más o menos directa a esta categoría. La sátira en todas sus vertientes textuales, los poemas heroico-cómicos, la poesía erótica, llevan consigo esta categoría estética. Y, por último, nuestras propias lecturas suponen una periferia dentro del ámbito de la lectura en general. Es decir, un poema de César Vallejo no será de igual manera valorado si soy quien lo interpreta o, por ejemplo, si la autoría es de Ricardo Senabre. El texto varía, se metamorfosea; pero únicamente cobra validez en palabras de Senabre, mientras que las mías permanecen en el anonimato. De igual manera podríamos decir que la existencia de un libro se debe únicamente en función de otro. Los criterios a los que obedece la valoración del libro me excluyen en tanto que lector. De ahí que mi lectura se sitúe en la periferia. Muchos autores se sitúan en la periferia a falta de escritores que escriban sus libros. Un ejemplo es el de Giambattista Casti, un autor que, a pesar de tener habilidad para el verso, no pasa de ser mediocre, sobre todo, por haber malgastado esa facilidad - según la opinión de algunos críticos - en componer sátiras y novelas galantes. Casti, a pesar de ser nombrado y en ocasiones de figurar en algunos manuales de la literatura italiana, no existe o existe solo dentro de la periferia. El impulso que lo conduce a ser considerado como un marginal es el que fascinará, por ejemplo, a muchos lectores del XIX, incluso algunos de la talla de Goya.

La periferia supone un posicionamiento intelectual válido. Al igual que el arte se aristocratiza, la literatura sufre el mismo proceso en dos direcciones. $\mathrm{O}$ existe soterradamente tras haber permanecido durante alguna época en la memoria de la comunidad, como es este último caso o el del Templo militante de Cairasco de Figueroa, o se dirige a un colectivo de iniciados. Sin embargo, incluso dentro de esta última postura, también hemos de distinguir dos tipos. A una literatura creada exclusivamente para el intercambio de conocimientos, escrita en un lenguaje solo al alcance de unos pocos, se encuentra una dirigida casi a un cónclave, cuyas referencias culturales son las mismas y fuera de este 
carece de sentido. Habremos pues de decidir en qué periferia nos movemos, conscientes de que, en cualquiera de los casos, nunca estaremos en el centro.

Teniendo en cuenta estos antecedentes, no resulta extraña la labor historiográfica de Menéndez Pelayo. Por un lado, mantendrá aquellas literaturas periféricas en el sentido estético en la heterodoxia y tratará de centralizar algunas obras de las literaturas periféricas en el sentido geográfico, como sucede con la literatura hispanoamericana. Señala Viviescas (2010: 40) que, en este caso, Menéndez Pelayo no trata de demostrar su singularidad, sino «la continuidad del proyecto cultural hispano y la pertenencia natural de aquella literatura a este proceso». La lengua castellana, continúa Viviescas, es el criterio dominante de esta comunidad cultural. De la misma manera, González-Stephan (2002: 230) afirma que «el español permitió vertebrar una racionalidad histórica que no hubiera sido posible dentro de los marcos del pensamiento liberal si se tomaban en cuenta las lenguas indígenas». Podríamos decir que el polígrafo santanderino tenía la misma «miopía canónica-lingüística un tanto onanista de Bloom» (García Barrientos, 2013: 65).

Le debemos a Menéndez Pelayo, qué duda cabe, haber dado forma a las expresiones literarias hispánicas que, sin su intervención, hubieran quedado relegadas al olvido. Como señala Garrido Gallardo (2012), su labor de establecer las líneas por las que debían transitar los estudios sobre literatura española y el carácter abarcador de su obra precisaban matizar sus aportaciones, como sucede con la preceptiva dramática del XVII. De igual modo, las observaciones que el polígrafo santanderino realiza sobre muchos autores en su ingente epistolario y en obras como Historia de las ideas estéticas, Historia de la poesía hispano-americana, Historia de los heterodoxos españoles o Estudios y discursos de crítica histórica y literaria, supusieron que aquellos autores fueran ubicados en la periferia, en tanto que escapaban de las características que fijara el «canon oficial». Estos autores se sitúan en la marginalidad por la temática que abordan (pensemos, por ejemplo, en Giambatista Casti o Nicolás Fernández de Moratín) y por la ideología que dejan traslucir sus obras. En este sentido, resulta interesante ver el discurso que desarrolla Menéndez Pelayo, no exento de violencia, hacia quienes considera malos poetas.

Helmut C. Jacobs, al abordar el desarrollo del buen gusto en el siglo XIX, había señalado de qué forma Menéndez Pelayo (2001: 269): «para legitimar exclusivamente sus valoraciones estéticas [...] se considera a sí mismo como un "hombre de gusto" y cree firmemente la existencia de unas reglas reconocidas, obligatorias y en última instancia universales del buen gusto», de la misma manera, apuntamos, que establece Bloom.

El discurso de Menéndez Pelayo, que calará en la crítica española del siglo XX, es la constatación de algo que subrayarán las escrituras periféricas, a saber: que la literatura «española» no siente su aportación como propia. Ello había llevado, en su tiempo, a que el ilustrado José de Viera y Clavijo corona- 
ra su Noticias de la historia general de las Islas Canarias con un breve diccionario biográfico de escritores (1982) o que un poeta como Graciliano Afonso (2007), en su prólogo a la Oda al Teide (1853), planteara una suerte de canon de la literatura canaria en torno al tema-símbolo del pico insular en su «Advertencia preliminar». Lo interesante de esta propuesta, dirigida al lector canario, es que presenta a autores conocidos, como Cairasco, Viana, Tomás y Juan de Iriarte, Viera y Clavijo o Clavijo Fajardo, junto con autores cuyas obras circulaban de manera minoritaria o manuscrita. Indudablemente, en esta revisión, aparecerán autores canónicos de la época: (el divino) Cervantes, Lope de Vega, Petrarca, Tasso, Ariosto, Enrico Wanton, Chateaubriand, Virgilio, Meléndez Valdés, Quintana, Garcilaso, Rodrigo Caro, Villena, Dupaty, Horacio, Anacreonte, Lobo, Calderón, Aristóteles, Byron, Propercio, Fray Luis de León («el Horacio español, el cisne del sesgo Tormes», Afonso, 2007: 222), Byron, Walter Scott, Gray, Warton, Coleridge, Southey, Montgomery, Campbell, «el francés amanerado Lamartine» (Afonso, 2007: 223) y Jáuregui. Algunos de los autores ingleses citados por Afonso coincidirán con los que propondrá Alcalá Galiano desde Londres en 1834 (Navas Ruiz, 2002), pero parten de lecturas y contextos diferentes. Mientras el primero había elegido el camino del exilio americano y permanecerá un tiempo en Trinidad de Barlovento, donde conocerá la obra de Montgomery, el segundo había optado por el exilio europeo y conectará con los románticos ingleses, que propondrá como autores canónicos a los jóvenes españoles (Navas Ruiz, 2002).

En todos estos casos, nos situamos en la perspectiva del lector en tanto que creador de cánones que combinan la memoria literaria de una época con la memoria literaria del lugar desde donde se lee y se escribe. Estas obras canonizadas por los lectores responden, indudablemente, al placer estético que proporciona su lectura o, como lo describía Borges, «la emoción singular llamada belleza, ese misterio hermoso que no descifran ni la psicología ni la retórica» (1988: 5). Sin embargo, lo que a Borges no le proporcionaba esa emoción, por ejemplo, García Lorca (Canto, 1999), nos lo puede proporcionar a nosotros. Si bien ha habido tentaciones de emparentar al escritor argentino con Bloom (Gamerro, 2012), hay un aspecto que apunta Julio Ortega (2007: 673) sobre Borges que lo sitúa en sus antípodas:

Como Darío, Borges excedió las fronteras de la lectura. Convirtió a la filología en hermenéutica demostrando que un texto nunca está del todo acabado (sin origen ni fin, anticipando la crítica genética); subvirtió la tradición con el relativismo crítico (el Quijote es siempre, gracias al lector, otro Quijote); puso en duda el Archivo y el Museo de los saberes (una página de más torna incompleta a la Enciclopedia); reconoció la irreverencia creativa de los márgenes (en español somos dueños de todas las literaturas y no tributamos el gravamen de la nacional); y descreyó del sujeto del optimismo modernizador (el yo no es héroe del lenguaje, apenas su sílaba alterna). 
Ahora bien, Bloom se aleja de cualquier diálogo, como en su tiempo había hecho Menéndez Pelayo. Como señala Grínor Rojo (2011: 7):

Nadie que no sea Harold Bloom se atreve en los tiempos que corren a definir qué es «lo literario», ni menos todavía a delimitar, jerarquizar, tirar rayas, levantar y cortar cabezas en nombre de esa definición.

[...] es un hecho que ninguno de los tres criterios que avalan toda la teorización occidental existente en torno a este problema, a los que se ajustan de una u otra manera todas las distinciones bloomianas, que son el criterio de retoricidad, el de ficcionalidad y el de universalidad, nos parece hoy día digno del mismo crédito que estábamos dispuestos a acordarle en tiempos no demasiado lejanos.

En estas páginas he tratado de reflexionar acerca de algunos criterios para la inserción de la periferia o lo periférico como categoría dentro de una hipotética biblioteca de Occidente. Es una propuesta que meritaría de mayor espacio y reflexión, pero que tiene como principal fundamento la necesidad de replantearse los límites del canon en tanto que proceso de apropiación de un determinado grupo de lectores de todas las lecturas, aun cuando, de acuerdo con Emerson (Fuentes, 2011) y con Borges, todas las obras están contenidas en un autor y, por consiguiente, todas sus lecturas. La periferia, por tanto, debiera ser centro, puesto que, al final, toda producción literaria no deja de ser una suerte de isla que reclama para sí su espacio. En este sentido, vale la pena, frente a las opciones críticas que tratan de negar la existencia de otras expresiones que no partan del centro, y que establezcan criterios estéticos en los que solo cabe unas determinadas obras, hacerse eco del deseo de Eugenio Padorno (2003: 19-20):

Quiero pensar que la prosperidad de lo que he llamado una democracia del espíritu tiene que ver con la opinión del poeta y pensador martiniqués Edouard Glissant en el sentido de que a todos nos aguarda la imparable multiplicación de periferias que se trasforman en centros y de continentes que se transforman en archipiélagos. Ojalá que este proceso no suponga el tributo del absoluto desgaste de las singularidades que a cada comunidad distingue.

\section{BIBLIOGRAFÍA CITADA}

Afonso, Graciliano (2007). Antología poética. Antonio Becerra Bolaños (int., ed. y not.). Islas Canarias: Academia Canaria de la Lengua.

Ayala Aracil, M. ${ }^{a}$ de los Ángeles (2005). «El artículo de fondo: una parodia del escritor público», en Yolanda Arencibia, María del Prado Escobar y Rosa María Quintana (ed.), Actas del octavo congreso internacional de estudios Galdosianos. Las Palmas de Gran Canaria: Cabildo Insular de Gran Canaria, pp. 520-527.

Bloom, Harold (2012). Novelas y novelistas. El canon de la novela. Eduardo Berti (trad.). Madrid: Editorial Páginas de Espuma.

Boileau, Nicolas (1862). Le lutrin. Lyon: N. Scheuring, libraire-editeur. 
Borges, Jorge Luis (1988). Biblioteca personal (prólogos). Madrid: Alianza Editorial.

Bou, Enrique (1989). «Parodia en "Tristana": lecturas de Galdós», Revista hispánica moderna. 42(2), pp. 115-126.

Cabañas, Pablo (1967). «Moratín en la obra de Galdós», en Jaime Sánchez Romeralo y Norbert Poulussen (dir.), Actas del Segundo Congreso Internacional de Hispanistas. Holanda: Instituto Español de la Universidad de Nimega, pp. 217-26.

Calvino, Italo (1993). Por qué leer los clásicos. Aurora Bernárdez (trad.). Barcelona: Tusquets Editores.

Calvino, Italo (2012). Seis propuestas para el próximo milenio. César Palma (ed.); Aurora Bernárdez y César Palma (trad.). Madrid: Siruela.

Canto, Estela (1999). Borges a contraluz. Buenos Aires: Espasa Calpe.

Coffey, Mary L. (2009). «De profecía a parodia: Galdós y el republicanismo español», en Yolanda Arencibia y Rosa María Quintana (ed.), Actas del noveno congreso internacional de estudios Galdosianos. Las Palmas de Gran Canaria: Cabildo Insular de Gran Canaria, pp. 312-319.

Colinas, Antonio (2002). «La literatura de la memoria», en Domenico Antonio Cusato, Loretta Frattale, Gabriele Morelli, Pietro Taravacci y Belén Tejerina (ed.), Letteratura della memoria. Atti del XXI Convegno Salamanca 12-14 settembre 2002. Messina: Andrea Lippolis Editore, pp. 71-84.

Davis, Stuart (2001). «In Defence of an Institution: Approaches to the Peninsular Spanish Canon», Journal of Iberian and Latin American Studies. 7, 2, pp. 129-142. doi: 10.1080/14701840120104809.

Díez Borque, José María (2007). «Bibliotecas y novela en el Siglo de Oro», Hispanic Review. 75 (2), pp. 181-203. doi: 10.1353/hir.2007.0008.

Dussel, Enrique (1994). 1492. El encubrimiento del Otro. Hacia el origen del «mito de la Modernidad». La Paz: Plural editores.

Fuentes, Carlos (2011). La gran novela latinoamericana. 5. ed. México: Alfaguara.

Gadamer, Hans-George (1998). Verdad y método II. Manuel Olasagasti (trad.). Salamanca: Ediciones Sígueme.

Gamerro, Carlos (2012). «Harold Bloom, lector de Borges, y viceversa», en Carlos X. Ardavín Trabanco y Antonio Lastra (ed.), La influencia de Harold Bloom. L'Eliana (Valencia): Nexofía, Libros Electrónicos de la Torre del Virrey, pp. 105-121.

García Barrientos, José-Luis (2013). «El teatro, los géneros, las lenguas y la historia en la Biblioteca de Occidente», en Miguel Ángel Garrido Gallardo (ed.), La Biblioteca de Occidente en contexto hispánico. Madrid: UNIR Editorial, pp. 57-71.

Garrido Gallardo, Miguel Ángel (2012). «Don Marcelino, Juan de la Cueva, Lope de Vega y la preceptiva dramática», Ángeles Ezama, Antonio Martín, Marta Marina y Rosa Pellicer (ed.), Aún aprendo. Estudios dedicados al profesor Romero Tobar. Zaragoza: Universidad, pp. 427-438.

Gómez Castellano, Irene (2010). «Deconstruyendo a Galdós: La "traducción” de Fernando Ortiz de "El caballero encantado"», Bulletin of Hispanic Studies. 87(3), pp. 291-311. doi: $10.3828 /$ bhs.2010.2.

Gómez de la Serna, Ramón (1985). Prólogo a la obra de Silverio Lanza. Buenos Aires / Madrid: Biblioteca personal de Borges / Hyspamétrica.

González-Stephan, Beatriz (2002). Fundaciones: canon, historia y cultura nacional. La historiografia literaria del liberalismo hispanoamericano del siglo XIX. Madrid: Iberoamericana.

Jacobs, Helmut C. (2001): Belleza y buen gusto. Las teorías de las artes en la literatura española del siglo XVIII. Beatriz Galán Echevarría (trad.). Madrid: Iberoamericana. 
Juaristi, Jon (1990). «Ironía, picaresca y parodia en La de Bringas», Nueva Revista de Filología Hispánica. 28, pp. 277-296.

Juaristi, Jon (1994). «Lengua y dialecto en la literatura regional: el caso bilbaíno», en José

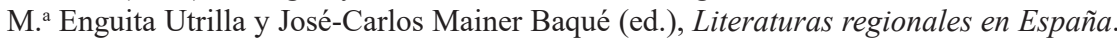
Zaragoza: Instituto «Fernando El Católico», pp. 49-82.

Kronik, John W. (2005). «Galdós y sus críticos: el galdosismo en América», Actas del octavo congreso internacional de estudios Galdosianos. Las Palmas de Gran Canaria: Cabildo de Gran Canaria, pp. 848-853.

Lasarte Valcárcel, Javier (2003). «El XIX estrecho: leer los proyectos fundacionales», en Friedhelm Schmidt-Welle (ed.), Ficciones y silencios fundacionales. Literaturas y culturas poscoloniales en América Latina (siglo XIX). Madrid: Iberoamericana, pp. 47-77.

Lluch Crespo, Gemma (2009). Literatura infantil y juvenil y otras narrativas periféricas. Alicante: Biblioteca Virtual Miguel de Cervantes.

Martínez Palacio, Javier (1971). «Miseria y parodia galdosiana de la Restauración», Ínsula: Revista de Letras y Ciencias Humanas, 291, pp. 4-5.

Melo Franco, Francisco (1822). A Estupidez. Lisboa: João Esteves. Disponible en: <http:// books.google.es/books?id=1RYTAQAAMAAJ\&hl=es\&pg=PR1\#v=onepage \&q\&f=false $>$ [ref. de 3/3/2017].

Menéndez Pelayo, Marcelino (1886). Historia de las ideas estéticas en España. Tomo III (volumen segundo). Siglo XVIII. Madrid: Imprenta de A. Pérez Durrull.

Navas Ruiz, Ricardo (2002). «El canon poético en España de 1830 a 1837», en Luis F. Díaz Larios, Jordi Gracia, José M. ${ }^{a}$ Martínez Cachero, Enrique Rubio Cremades y Virginia Trueba Mira (ed.), La elaboración del canon en la literatura española del siglo XIX: II Coloquio de la Sociedad de Literatura Española del Siglo XIX (Barcelona, 20-22 de octubre de 1999). Alicante: Biblioteca Virtual Miguel de Cervantes, pp. 299-312.

Noroña, Conde de (1997). Antología poética. Santiago Fortuno Llorens (ed.). Madrid: Cátedra.

Ortega, Julio (2007). «El hispanismo y la geotextualidad atlántica», Bulletin of Spanish Studies: Hispanic Studies and Researches on Spain, Portugal and Latin America. 84 (4-5), pp. 671-676. doi: 10.1080/14753820701452766.

Padorno, Eugenio (2003). Del lugar del existir. Islas Canarias: Academia Canaria de la Lengua.

Peláez Pérez, Víctor Manuel (2007). La época dorada de la parodia teatral española (18371918) (Tesis doctoral). Universidad de Alicante. Disponible en: $<$ http://rua.ua.es/dspace/ bitstream/10045/12736/1/tesis_pelaez.pdf> [ref. de 3/3/17].

Pope, Alexander (1851). El rizo robado, traducido del castellano por el traductor del Ensayo de la Crítica [Graciliano Afonso], del mismo autor. Las Palmas de Gran Canaria: [s.n.].

Reyes, Alfonso (1997). «Los "caracteres" de la obra literaria», en Alfonso Reyes, El deslinde. Apuntes para la teoría de la literatura. Obras completas de Alfonso Reyes, XV. México: Fondo de Cultura Económica, pp. 425-446.

Rodríguez, Alfredo (1966). «Algunos aspectos de parodia lírica en Galdós», Ínsula: Revista de Letras y Ciencias Humanas. 234, p. 13.

Rodríguez Padrón, Jorge (2007). La memoria y sus signos. Tenerife: Ediciones Idea.

Rojo, Grínor (2011). Clásicos latinoamericanos. Para una relectura del canon. El siglo XX. Vol. II. Santiago de Chile: LOM Ediciones.

Román Román, Isabel (1990). «Galdós y la parodia del estilo bíblico», Anuario de estudios filológicos. 13, pp. 355-362. 
Román Román, Isabel (2006). «Humor y parodia en Galdós», Yolanda Arencibia y Ángel Bahamonde Magro (coord.), Galdós en su tiempo. Santa Cruz de Tenerife: Parlamento de Canarias, pp. 189-212.

Sánchez Robayna, Andrés (1994). «Literatura e historia: el caso de Canarias», en José María Enguita Utrilla y José-Carlos Mainer Baqué (ed.), Literaturas regionales en España. Zaragoza: Instituto Fernando El Católico, pp. 49-82.

Schraibman, Joseph (1984). «Una parodia de una parodia: Juanito Santa Cruz y Moreno-Isla», El Museo Canario. 44, pp. 83-91.

Viera y Clavijo, José de (1982). Noticias de la Historia General de las Islas Canarias. A. Cioranescu (int. y notas). Santa Cruz de Tenerife: Goya Ediciones.

Viviescas, Víctor (2010). «La cuestión latinoamericana como problemática de las historias de la literatura latinoamericana», en Carmen Elisa Acosta Peñaloza (ed.), Representaciones, identidades y ficciones. Lectura crítica de las historias de la literatura latinoamericana. Bogotá: Universidad Nacional de Colombia, pp. 31-88.

Zavala, Iris M. (2010). Las siente plagas y sus paradojas. Puerto Rico: Letra y Píxel.

Fecha de recepción: 6 de octubre de 2014.

Fecha de aceptación: 12 de marzo de 2015. 